\title{
Advances in Public Perception of Metrology in the Republic of Cuba
}

\author{
Ysabel Reyes-Ponce*, Alejandra Regla Hernández-Leonard
}

National Metrology Research Institute (INIMET), Cuba

Copyright $\odot 2016$ by authors, all rights reserved. Authors agree that this article remains permanently open access under the terms of the Creative Commons Attribution License 4.0 International License

\begin{abstract}
Results of a research into the Cuban society's current perception of Metrology, based on case studies conducted in seven enterprises in Havana, are presented. The possibility to have a positive impact on the Cuban people's knowledge about this topic through well-designed actions aimed directly at meeting their previously identified training needs is demonstrated. It was used the method of research and action. Developed books and teaching materials about metrology, contribute to the elevation in Cuba of the society's scientific culture and the public perception of science and technology.
\end{abstract}

Keywords Public Perception of Science, Scientific Culture, Metrological Culture, Metrology

\section{Introduction}

A new field of knowledge focused on the study of the "public perception of science" and society's "scientific culture" has been gaining ground in the last few years.

From the conceptual viewpoint, Polino C., Fazio M.E., Vaccarezza L. (2003)[1], among others, believe that, even if both terms are often believed to be synonymous, the former is actually referred to the process of social communication and its effects on the formation of knowledge, attitudes and expectations in society, while the latter has a more complex origin and composition. In fact, when defining the term "scientific culture" we should not only think about all the knowledge, attitudes, expectations, abilities and skills of an isolated individual, as we consider the term "culture" as being essentially linked with "society".

Whereas science and technology are part of society in the form of institutions, systems and processes, society in turn defines the branches of science and technology that it is interested in developing. Therefore, it is always interesting to discuss and appraise whether science, technology and society are sufficiently integrated into each other to help knowledge become the content that society will subsequently put into general practice as an element of its members' common sense. To this end, a framework must be provided to study and evaluate science's function and performance within society's cultural and productive dynamics. All efforts should then be channeled into the design and implementation of clear-cut, well-structured policies that will make it possible to overturn any setbacks and boost any positive outcome.

Surveys on the perception of scientific culture are regularly carried out in the European Union, Australia, Canada, China, United States, Great Britain and Japan. Some Spanish-speaking countries, namely, Argentina, Brazil, Spain and Uruguay, have done qualitative studies and polls centered upon people's perception of science and technology. Mexico and Panama have some governmental experience in this kind of measurement. Cuba has just started to work hard in this field, using research protocols to assess people's levels of perception, scientific culture and participation in science and technology and establish the proper indicators.[2 - 9]

Launched in 2005 mainly by a group of researchers from Cuba's National Research Metrology Institute (INIMET), this work was focused on society's perception of Metrology and the level of metrological culture in seven organizations selected according to their economic relevance and social purpose [10]. Three of them are production enterprises involved in the manufacture of doors; prefabricated metallurgical units; construction equipment; fragrances for perfume, soap and cream production; injectable pharmaceuticals; veterinary drugs, and yoghourt. The other four are service organizations, two involved in hotel management and two in project development.

Once a preliminary diagnosis was made, specific improvement action was undertaken in order to modify the workers' views of, knowledge about and interest in Metrology.

For the purposes of this research, metrological culture was understood as the intellectual level achieved after a learning process about measurements and units of measurement, measuring instruments and methods and other related 
subjects, with the hopes that we would help people to both assume a more proactive attitude toward the defense of their rights as consumers of goods and services and increase their overall culture.

\section{Materials and Methods}

Since the dawn of civilization, measurements have been paramount to society's scientific-technical development. No technological production, service or research process can exist today without the use of measuring equipment.

Metrology is the scientific basis on which all measurement processes are developed, and it plays a major role in every country's daily life and economic progress, regardless of its level of development. However, this fact is hardly in keeping with the Cuban society's perception of Metrology.

Faced with this situation, INIMET was charged with the design of an action plan to increase the level of metrological culture in Havana-based enterprises, and the resulting study included middle-sized and big enterprises involved in production (veterinary drugs, cosmetics and foods) and services (industrial design, housing and social projects, hotel management and food sales).

The methods implemented emphasized three major subjects: interests, knowledge and attitudes of the assessed individuals, supplemented with subsequent interpretations of the results achieved. The inquiring strategy covered three interrelated levels of analysis:

a) Degree of knowledge among selected workers about Metrology and the organization's metrological obligations.

b) Degree of knowledge among these individuals about their own organization and its metrological processes.

c) Existing level of metrological culture based on the workers' perception of the role played by Metrology in the fulfillment of their goals.

The results of the work allowed, on one hand, to discuss and assess the population sample's perception of Metrology, and on the other, to implement actions to increase metrological culture in the sample organizations and the Cuban society as a whole.

Given their significance, we list hereinafter the benefits derived from our study and others from recent incorporation:

\subsection{Instruction Manual to Make a Metrological Diagnosis ()}

As a first step in our research we made a diagnosis of the situation in the target enterprises. To that end a number of properly reliable tools were created that provided information about the existing levels of metrological culture and consumer protection. We used these tools to develop a scientific-technical methodological and organizational document called "Instruction manual for the diagnosis of metrological performance" [11] that we registered with CENDA (Cuba's Copyrights Center). This manual made it possible as well to have all the elements we needed to design actions for improvement in these enterprises using the knowledge about the status of the existing organizational culture regarding Metrology.

The following methods were used to develop the Manual:

- Interviews with key staff in charge of the functions included in the scope of the diagnosis and surveys among managers and technicians to assess their level of awareness of the studied topics and general knowledge about the organization and identify the prevailing opinion about these subjects.

- Analysis of the organization documentation to establish Metrology's position in the flow diagram, the level of metrological management pursuant to the process requirements, and whether the relevant regulations were being fulfilled.

- Gather evidence on site during the metrological survey to assess the status of the equipment, the use of legal units of measurement and certified reference materials, and the existing needs.

- Exchange experience on site with the relevant staff about the measuring process to identify weaknesses and opportunities for improvement in every workstation.

One of the tools included in the Manual is a metrological survey that includes 26 variables aimed at getting information about the measuring and testing equipment and the reference materials, for instance, their denomination, role within the process, original purpose, brand, model, country, date of manufacture, metrological characteristics, technical condition, and date of the last metrological control. In the case of the reference materials, we stated whether or not they are certified, information about the certifying body, and the needs of measuring and testing equipment and reference materials.

Our survey also gave us information about the units of measurement used to express the results in order to define whether non-legal units were used at any time and make plans to implement the International System of Units (SI).

For the interviews we identified the General Director of each organization as key staff, and they had the chance to express their points of view, individual qualification, and willingness to correct the detected problems.

The survey answered by technicians and managers who were directly involved in measurement includes three types of questions addressed at the following objectives:

Type I, to evaluate their knowledge about these topics;

Type II, to request information;

Type III, to identify the prevailing opinion about these topics.

Type-II and -III questions provided the most widespread opinions about the required performance established in the reference documents or by the organization. Thus we found out what the surveyed staff thought about Metrology, its importance in the production or service process, and the operation of the organization. The purpose of this information was to correct any deviation. 


\subsubsection{Statistical and Functional Validation of the Survey}

In order to make sure our survey provided reliable, homogeneous information, we made a statistical validation using Cronbach's alpha, a very common psychometric coefficient to measure survey reliability, as shown by Oviedo and Campos-Arias (2005)[12]. Thus we evaluated an index of internal consistency with values ranging from 0 to 1 . Most authors agree that values between 0.70 and 0.90 show a proper internal consistency.

Before calculating the reliability of the test using Cronbach's alpha, we checked the fulfillment of two prerequisites:

1. That the test included a set of items that are additively combined to find an overall score (ie, what we're interpreting is the sum of the scores).

2. That all items measured the desired characteristic in the same direction (ie, the items in each of the scales are responded in the same direction).

After analyzing the statistical functions, the items whose item-total coefficients yielded values less than 0.35 were reformulated or discarded, considering that a low correlation between the item and the total score can be due to various causes, whether poor item writing or that it is not appropriate to measure what needed to be measured.

A first draft of the survey was filled by the authors. At this stage the bias introduced by the obvious fact that the authors of the survey knew the correct answers and the objective of these was disregarded. However, as a result of the exercise some questions must be reformulated for reasons of ambiguity or because they inciting a specific answer or multiple answers. Moreover, two or more items asking the same were integrated into a single question.

Once the necessary adjustments were made, the second draft of the survey was developed which was applied to a group of twelve managers of one of the enterprises targeted by the project.

This time, the results of the exercise revealed the need to either reformulate other questions, or to increase the options to answer, mainly in the case of types II and III questions.

Again, a third version was subjected to examination by the research group, which also analyzed the results, the influence of the order and phrasing of the questions, and the relevant input provided by each question in order to meet the goal of evaluating the level of knowledge of those polled about the topics at issue.

The Cronbach coefficient calculation was performed using the variance of the items and the variance of total score, using the equation:

$$
\alpha=\left[\frac{K}{K-1}\right]\left[1-\frac{\sum_{i=1}^{k} S_{i}^{2}}{S_{t}^{2}}\right]
$$

where :
$S_{i}^{2}$ - is the sum of variances of each item.

$S_{t}^{2}$ - is the variance of the total of rows (total score of the participants)

$\mathrm{K}$ - is the number of questions or survey items.

For evaluation we only took into account questions type I, being those that meet the prerequisites of the evaluating tool.

In order to analyze the validation results statistical functions were calculated. In doing so, were obtained two kinds of results: those that related items with the scale, and those that presented items in relation with the total score. The second kind of results is highly relevant because it indicates the linear correlation between the item and the total score (excluding the item in evaluation) indicating the extent and direction of this relationship.

These two tables of results were essential for the interpretation and possible rephrasing of the survey.

The Cronbach's alpha obtained for the metrological diagnosis survey is 0.78 , for all 22 type I items included. A total of seven items gave correlations which were less than 0.30 , and although they were used in the survey, they could be eliminated without detriment to its homogeneity and internal consistency. On the contrary, it would make it even more consistent, as it would raise the Cronbach's alpha to 0.85 .

The resulting version of survey was included in the Instruction Manual and applied to more than 50 managers and 60 employees of the seven enterprises participating in the project.

For its functional validation, the survey was applied by seven different researchers to a wide cross section of over 100 managers and employees in the organizations. The results achieved confirm the validity of the survey given the low sensitivity to the differences between the survey-takers and the respondents.

The overall level of staff knowledge was evaluated from the percentage of correct / satisfactory answers to the type I questions, as follows:

Less than $50 \%$ - Very low level

$50 \%$ to $70 \%$ - Low level

$70 \%$ to $90 \%$ - High level.

$90 \%$ to $100 \%$ - Very high level.

In the stages very low level and low level, it was recommended to the enterprise to take action to raising the metrological culture, including, primarily, training of managers, officials and employees directly related to the metrological functions and actions.

The questions types II and III allowed us to obtain information about the enterprise, and identify the state of opinion about the investigated issues. Because these questions had several response options, the frequency of each response and the percentage that each represents, relative to the total of respondents in each occupational category were reported. 
We examined the most widespread opinions, and proximity or not to the provisions of reference documents. Then we made relevant recommendations to assist the assessed enterprise to correct the detected deviations.

As confirmed by both the data and the results about the existing knowledge, one enterprise scored as a high level organization, while the others received qualifications ranging from low level to very low level. None was found to be at very high level.

The findings of the diagnosis allowed us to identify opportunities for management improvement, namely:

a) Provide training on Metrology, metrological assurance and consumer protection.

b) Carry out the metrological control of all measuring instruments used in the main production or service processes and to provide internal services in the organization.

c) Pay attention to the location and performance of the metrological activity within the structure and organization of the enterprise with a view to facilitating its execution.

d) Guarantee the traceability of measurements.

e) Design a program for the full implementation of the SI units.

f) Remake the register of all measuring instruments in the organization so as to include metrology-related and other important data such as: measuring range, class, error, uncertainty, brand name of instruments, model, country and year of manufacture, date of its last calibration or verification, and technical condition.

g) Get the tools and instruments needed to repair and control measuring instruments in a proper way.

h) Fill in the organization's documents with the elements that contribute to the adequate development of metrological management.

Although it was not part of the research, we led all target organizations to design an action plan to find short-, medium- and long-term solutions to the findings of their metrological work. Among the main items in this plan were the funding of metrological obligations and the revision of their organizational structure.

One major result of our project was the identification of training needs among the specialists from the favored enterprises and the design of specific actions to meet them. Once we defined the current level of metrological culture of these individuals we were able to introduce the proper mechanisms to improve it.

In the period when the research was developed many Cuban organizations have undertaken a process to improve and certify their Quality Management System to the NC ISO 9001:2008 standard, "General requirements of a Quality Management System". At present they are introducing the new 2015 version of this standard, in which risk aspects in metrology play a significant role in the provision of products and services of sufficient quality to be competitive in international markets.
In our experience, failure to be thorough in the execution of metrological works has a negative impact on process and product quality and paves the way for a poor management of resources and metrological violations linked to a lack of confidence in the quality of measurements made in various economic areas and consumer protection practices, to name a few consequences.

In this regard, man is at the center of any action designed to assure the proper process quality and performance. Therefore, the staff must have the necessary qualification and skills to increase the level of metrological management in their organization and identify any strength, weakness, opportunity and threat in order to plan for improvement.

\subsection{Teaching Aids to Train Human Resources Involved in Measurement}

The following topics must be covered:

Metrology: Importance and prospects.- Legal Metrology and the SI System - Product testing: a guarantee to consumers - Laboratory Accreditation - Uncertainty of Measurements, the basis of mutual recognition and the elimination of technical barriers to trade - Industrial Metrology and Mass Quantity Metrology. Volume measurements - Consumer protection.

Involved in the process were experienced professionals in both Metrology and Consumer Protection fields using the most current documents and bibliography on the subject.

\subsection{Revised Reprint of the Information Booklet "International System of Units (SI)"}

This booklet was updated to the eighth edition in 2006 of the brochure Le Système International d'Unités, published by the International Bureau of Weights and Measures (BIPM), the Supplement 2014: Updates to the $8^{\text {th }}$ edition (2006) of the SI brochure and the new ISO 1000 and ISO 80000 standards. All definitions of the basic units and the rules to write symbols and quantities were revised and updated with the help of the Metrology Division of the National Bureau of Standards.

Designed to be used in Cuban schools at all levels of education, the booklet is also useful to professionals and citizens in general, as it includes the SI and other units legally applied in Cuba and related information.

\subsection{Training Actions in the Target Organizations}

Eight training workshops were organized for 252 specialists from the organizations which benefited from our research and other interested enterprises. We also trained their Board members in subjects like Metrology and Consumer Protection, and upgraded the staff's level of metrological culture through exchanges organized during the fieldwork. 


\subsection{Introduction of a New Courses and Redesign of Another as Part of INIMET's Training Service Program}

The experience in workshop organization made it possible to extend the training activity by redesigning courses on Metrological Assurance introduced in INIMET's qualification program and given to specialists from national economy, and more of 400 specialists of metrology for the national service, with good results. In reply to requests from several organizations, the new courses were added to teach how to use the Manual of Instruction to carry out a metrological diagnosis, also with good results.

\subsection{Course, tabloid and Book "Metrología Para la Vida $\odot$ " [13 - 15] (Metrology for Life) for the Scientific Dissemination of Metrology}

The course Metrology for Life, offered through the TV program Universidad para Todos (University for All) in one-hour, nationwide broadcasts for 16 weeks, together with a two-part 32-page tabloid and a book with the same title, have been an important resource to disseminate this science and improve the Cuban people's metrological culture. This course was very popular and extremely useful to bring Metrology to the fore, as it took this science to every home and allowed the population to get acquainted with the basic tools to carry out proper measurements. Sold at a very reasonable price at newspaper stands across the country, the tabloid includes part of the content found in the book, namely the following subjects:

An Overview of Metrology - Consumer Protection in Cuba: Challenges and Prospects - Product Testing: A Guarantee to Consumers - Past, Present and Future of the International System of Units in the Republic of Cuba Calibration and Traceability. An Approach to the Uncertainty of Measurements - Metrological Assurance of the National Economy.

The book "Metrology for Life" was registered with the Cuban's Copyrights Center and was twice edited.

\subsection{Metrology and the Forms of Non-state Employment [16]}

Product quality, regardless of its origin, must be such that customer satisfaction and consumer protection can be ensured. Implicit therein, as guarantors, are standardization and metrology, each with their own role to help the relevant product or service meet the above requirements and fulfill their expected purpose.

Our country has strived to develop this kind of business in the form of cooperatives, small farmers, leasing, etc. These forms of microbusinesses foster the replacement of imports and a greater diversity of products available to the population.

This is highly important in Cuba, as we need to find the best solutions, taking into account our specific conditions and given the legalization of non-state employment, which uses a different language from the state sector regarding metrological assurance and control, although we must see to it that the existing rules and regulations -common to both sectors- are met at all times. Bear in mind that this is an emerging sector with no previous training or knowledge to ensure a swift adjustment to the demands of standardization, metrology and quality work.

Some self-employed workers identify with the need to carry out on-the-job measurements, but they are not totally sure about the kind of measurement that needs to be made, let alone the need to assure them or how to do it, then, the main weakness is related to the lack of knowledge about the importance of measurements and their assurance.

It was very important in this sense the organization of workshops and designing of the specific teaching materials, which include good practices related to the use of reliable measuring instruments. This is, among others, one of the best ways to fulfill the expected goal of guaranteeing service quality in non-state forms of employment.

\subsection{Writing and Publication of the Textbook "Fundamentals of Metrology" [17]}

The recent publication of the book Fundamentos de Metrología $\odot$ (Fundamentals of Metrology) in November 2014, made by highly qualified specialists from INIMET and other national entities with many years of experience in Metrology, was a major contribution to this end.

Since Cuba's technical and professional education is going through an important stage of transformation of the pedagogical process, our literature about these topics is expected to meet the needs imposed by this new stage on the intellectual development of Cuban students.

This textbook about Metrology was designed to meet those needs. The contents of its 731 pages covering 22 subjects related to traditional quantities of wide-ranging application goes beyond the fundamentals of Metrology, including some emerging topics and fresh information about metrological management so important and topical as to be of great value to teach, and increase the general culture of Metrology for students and professors alike. Examples are presented along with exercises to support comprehension and a varied and updated bibliography for those interested to go into these topics in greater depth and thus enrich their knowledge.

The topics are: -General Metrology -Errors of measurement -Uncertainty of measurement -Physical Quantity -Measurement. Methods of measurement -Measuring equipment -Dimensional measurements -Mass measurements -Force and hardness measurements -Pressure measurements -Volume and flow measurements -Temperature measurements -Electrical measurements -Magnetic measurements -Time and frequency measurements -Chemical measurements -Ionizing radiations measurements -Automation and control of industrial processes -Nanotechnology-Technical 
competence of calibration and testing laboratories -Quality of measurements -Legal and normative infrastructure on Metrology.

This work is registered in the Cuban's Copyrights Center.

All the contributions and actions described above met their purpose, that is, contributing to the creation of an integrated culture of Metrology among professionals and people in general, in such a way that their new knowledge makes it possible for them to be more proactive in the defense of their rights as consumers of goods and services.

\section{Conclusions}

The tools employed to make a metrological diagnosis were designed from self-control indicators of metrological management directed toward customer satisfaction and consumer protection, and were useful to get reliable information about people's perception of Metrology and their level of metrological culture.

Both the current perception of Metrology in the diagnosed organizations and the positive change occurred in the mindset of managers and trainees allow us to assert that it is possible to make a positive difference in society's knowledge about the abovementioned topics by implementing well-designed actions directly aimed at fulfilling previously identified training needs.

The used methods and the results of all contributions presented are an important arrives to studies currently underway in Cuba about people's perception of science and technology and our society's scientific culture.

All of them met their goal of making as much information as possible accessible to everyone so that they can have a comprehensive view of Metrology and its applications and play a more active role as consumers of goods and services.

\section{Acknowledgements}

The authors extend their thanks to Jesús Bran Suárez for his contribution to the English version of this paper.

\section{REFERENCES}

[1] Polino C., Fazio M.E., Vaccarezza L. (2003) Medir la percepción pública de la ciencia en los países iberoamericanos. Aproximación a problemas conceptuales. Online Available from http://www.oei.es/revistactsi/numero5/articulo1.htm

[2] Vogt, C; Righetti, S; Figuereido, S; et al. (2003) Percepción pública de la ciencia. Estudios realizados en São Paulo y en Brasil y la búsqueda integrada de estándares nacional e internacionales. Revista Eureka sobre Enseñanza y Divulgación de las Ciencias. ISSN 1697-011X. Online Available from http://www.apac-eureka.org/revista

[3] Sequera, R. (2008) Apuntes sobre los estudios de percepción social de la ciencia y la Tecnología. Fundación Española para la Ciencia y la Tecnología. Online Available from http://www.upf.edu/psctacademy/_docs/ApuntesFecyt.pdf

[4] Acevedo-Díaz, J.A (2006) Relevancia de los factores no-epistémicos en la percepción pública de los asuntos tecnocientíficos. Revista Eureka sobre Enseñanza y Divulgación de las Ciencias, 3(3), pp 370-391. ISSN 1697-011X. Online Available from http://www.apac-eureka.o $\mathrm{rg} /$ revista

[5] Lozano, M. (2008) El Nuevo contrato social sobre la ciencia: retos para la comunicación de la ciencia en América Latina. Revista electrónica Razón y palabra, No. 65 ISSN 1605-4806 Online Available from http://dialnet.unirioja.es/

[6] Álvarez-Pomares, O. (2009) Percepción pública, cultura científica y participación ciudadana en ciencia y tecnología. Indicadores de cultura en ciencia y tecnología. Online Available from http://www.observatorio.mincyt.gov.ar/perce p.htm

[7] Jara-Guerrero, S., Torres-Melgoza, J. (2011). Percepción social de la ciencia: ¿utopía o distopía? Revista Iberoamericana de Ciencia, Tecnología y Sociedad, No. 17, Vol. 6, Abril 2011, pág.57-76. Online Available from http://www.revistacts.net/index.php?option=com_content\&vi ew $=$ article\&id=384:perception-social-de-la-ciencia-iutopia-odistopia\&catid $=101$ :articulos

[8] Carrillo-Delgado, M.A., Bermúdez-Mora, J.C., Bustos-Mora, G., Solís-Salazar, M, García-Madrigal, P. (2012). Percepción social de la ciencia y la tecnología en Costa Rica. Resumen ejecutivo. Universidad Nacional. Facultad de Ciencias Sociales. Instituto de Estudios Sociales en Población.. Online Available from http://www.oei.es/salacrsi/Resumencr.pdf

[9] Cámara-Hurtado, M., López-Cerezo, J.A. (2012) Political dimensions of scientific culture: Highlights from the Ibero-American survey in the social perception of science and scientific culture. Red de Comunicación de la Ciencia, la Tecnología y la Innovación. SAGE journals. Public understanding of science. April 2012. Vol.21 No. 3 369:384 Online Available from http://www.pos.sagepub.com/content/ 21/3/369.abstract

[10] Reyes-Ponce Y, Hernández-Leonard AR. Public perception of metrology in the Republic of Cuba. OIML Bulletin No. 2. April 2010; Volume LI: p. 30-34; ISSN0473-2812

[11] Reyes-Ponce,Y.; Hernández-Leonard, A.R.; Hernández-Álva rez, A.M.; Valdés-Pereira, N.; Hernández-Apaceiro, M.; Hernández-Ruiz, A.D.; López-Victorero, S. Manual de Instrucción para la ejecución del diagnóstico metrológico. Boletín Científico-Técnico INIMET. No. 2 2008;: p. 31-37; ISSN 0138-8576.

[12] Oviedo C.H.; Campos-Arias, A. (2005). Aproximación al uso del coeficiente Alfa de Cronbach. Rev. Col. Psiqui Vol. XXXIV No. 4 Pág. 527-580.

[13] Reyes-Ponce, Y.; Hernández-Leonard, A.R.; Hernández-Ruiz, A.D.; Miranda-LaÓ, L.M. Universidad para todos. Tabloides del curso Metrologia para la vida. Parte 1 y Parte 2 La Habana: Editorial Academia; 2009 ISBN 978-959-270-142-7.

[14] Reyes-Ponce Y, Hernández-Leonard AR, Hernández-Ruiz AD. Metrología para la vida. Primera ed. La Habana: Editorial Científico-Técnica; 2009 ISBN 978-959-05-0586-7.

[15] Reyes-Ponce Y, Hernández-Leonard AR, Hernández-Ruiz AD. Metrología para la vida. Segunda ed. La Habana: Editorial Científico-Técnica.; 2013 ISBN 978-959-05-0687-1. 
[16] Reyes-Ponce, Y; Sosa-Vera, R.C, Suárez-Palau, H.M et al. Metrology and the various forms of non-state employment. OIML Bulletin Vol. LIV, Number 4, October 2013
[17] Reyes-Ponce, Y. et al. Fundamentos de Metrología, Partes 1 y 2 La Habana: Editorial Pueblo y Educación; 2014; ISBN 978-959-13-2601-0. 